\title{
After Romanticism, psychoanalysis and postmodernism: New paradigms for theorising creativity
}

\begin{abstract}
While Romanticism, psychoanalysis and postmodern theory have provided the dominant paradigms for understanding creativity in the humanities in the past century, this paper argues that interdisciplinary engagement with sociobiology and the cognitive sciences might provide ground-breaking perspectives. Against the 'supra-rational', masculinist and solipsistic visions of creativity that have prevailed, the work of the sociobiologist Ellen Dissanayake and of the neuroscientist Antonio Damasio invite new ways of thinking about the role of the feeling body, femininity and mutuality in creative practice. This paper will survey Dissanayake's and Damasio's research to explore the possibility and desirability of a paradigm shift when it comes to understanding creativity, with poetry as a strategic focus for its argument. This paper is not interested in putting forward a new methodology for writing poetry but in recognising the embodied condition from which all poetry fundamentally arises.

Keywords: theorising creativity, poetry, science
\end{abstract}

\section{Introduction}

It was upon studying WB Yeats's poem 'Long-legged Fly' as a high-schoolliterature student that I was introduced to a mystical, 'supra-rational' theory of poetic creativity. The poem portrays Julius Caesar, Helen of Troy and Michelangelo channeling a mysterious and quiet genius as they work, in their respective ways, at preparing a battle plan, being beautiful and painting the Sistine chapel. Each stanza ends with the refrain: 'Like a long-legged fly upon the stream / His [or Her] mind moves upon silence. 'As a student I found the poem ethereal and compelling. However, what interests me now is the poem's mobilisation of an enduring mythos of creative practice.

That mythos of creativity, intimately associated with Romanticism, might be said to have three tropes, each of which inhere in Yeats's post-Romantic poem. To begin with, the poem's stanzaic refrain highlights how creativity is identified with the Wordsworthian faculty of the mysterious and imaginative 'mind'. While the feeling body was indubitably important to the Romantics, who opposed Enlightenment rationalism and Cartesian dualism, their numinous conceptualisation of the imagination often resulted in a paradoxical disembodiment of the creative 'spirit'. As Timothy Clark writes in The Theory of Inspiration: Composition as a Crisis in Romantic and Post-Romantic

Writing, Romantic inspiration is "less irrational than ... "supra-rational"' (Clark 1997: 2) - the term adopted by this paper. Notably, in Yeats's poem the body 
becomes something barely present, as the tenuous image of the long-legged fly suggests. Secondly, the poem makes apparent that creativity is associated with the masculine. While the beautiful Helen is included, she is a 'body' of art rather than the creator of art. Caesar and Michelangelo, by contrast, engender war strategies and religious paintings through the mysterious potency of their minds. Finally, it is also notable that the men's creative practice occurs in solitude, though it seems to connect with a shared resource or mystical tradition of sorts. Indeed, the poem delivers a rhetorical plea for audiences not to disturb the creative genius at his solitary work.

Contemporary theories of creativity, as Clark suggests, continue to engage this Romantic mythos, with writers' self-descriptions of the creative process being particularly 'notorious for accommodating romantic myths of creativity' (Clark 1997: 9), which effectively self-validate their own creative activity.

Nevertheless, as Thomas Busse and Richard Mansfield indicate in their survey of creativity research (Busse \& Mansfield 1980), psychoanalytic or psychological studies have become the norm. Albert Rothenberg argues that the unconscious is 'invoked more frequently in connection with creativity than with almost any other human actions or experience' (Rothenberg 1990: 48). However, for Rothenberg, the 'belief in the unconscious roots of creativity', like Romantic explanations of inspiration, forms 'a mystique.' Indeed, psychoanalytic accounts of creativity remain intimately bound up with Romantic thought - which should come as no surprise given that Romanticism, with its interest in the irrational and the individual, essentially 'invented' psychoanalysis (Faflak 2007).

In both Jungian and Freudian theory the unconscious appears as a primordial and mysterious force that powerfully informs art (from Oedipus Rex through to Wagner's Ring Cycle). Jung and the Freudian Surrealists (if not Freud himself) pursued strategies for producing art by tapping into the unconscious mind in much the same way as Yeats's geniuses are shown communing with some imaginative intelligence. Psychoanalysis acknowledges the body as the source of the unconscious desires and fears that inform creativity, but it views the body ambiguously, with Freud's case studies relying heavily on the putatively irrational and expressive bodies of women. Indeed, contemporary psychoanalytic explanations of creativity salvage the unconscious as a kind of masculine 'supra-rational' force; they promote, as Clark puts it, a masculine 'Romantic Orphian' myth of creativity in which the individual ventures into the 'hidden "depths" of the mind' to achieve 'a privileged mode of consciousness that overcomes Cartesian dualism' (Clark 1997: 29). In this way, the three patterns of Romantic creativity identified earlier still linger in psychoanalytic thinking: the mind is mystified; the masculine is the creative force; and the individual creator is presented as heroic.

The repetition of such patterns, which we might trace to longer-standing theories of creativity espoused in classical and Renaissance contexts, as outlined in studies such as John Moffitt's Inspiration: Bacchus and the Cultural History of a Creation Myth (2005), suggests a certain stasis or stalemate in thinking. This has not been entirely challenged by postmodern epistemologies. For instance, Marjorie Perloff's Unoriginal Genius (2010) may contest the Romantic mythos of individual creativity in poetry by highlighting citation over originality. However, the Derridean concept of language and creativity informing Perloff's work can be viewed as cognitively idealist (if not 'supra-rationalist') and implicitly masculinist - something that the work of Hélène Cixous and Luce Irigaray addresses.

Clark's study usefully historicises the Romantic mythos of creativity - and its subsequent variations - by evoking the rise of the bourgeois individual subject 
and the absence of the material audience/reader, on whom a powerful rhetorical effect is strategically imagined (1997: 30). Clark also brilliantly notes the estranging effects of transitioning from writing to self-reading during the creative process, which he argues leads to the sense of a 'fissure or hiatus in the structure of subjectivity' (19) and to the 'experience that meaning is always elsewhere'. His thesis is that 'effects that seem psychic, internal or psychological are often determined by the material parameters of composition' (40). Notwithstanding the persuasiveness of Clark's argument, the 'suprarational', patriarchal and solipsistic ideologies in theories of creativity might also warrant a different approach, which involves not just a materialist critique of traditional ways of theorising creativity but a genuinely refreshed epistemological approach - an approach that might theorise the significance of the feeling body to the creative act (something overlooked in Clark's focus on textuality), and that might acknowledge femininity and audiences as fundamentally implicated in the creative process.

This paper, inspired by the ground-breaking interdisciplinary work of Kevin Brophy in the area of creative writing, explores the possibility of achieving such reinvigoration through forays into disciplines outside the humanities. New, empirically based work in the fields of sociobiology and the cognitive sciences provides the potential for understanding creativity in ways that challenge myths of inspiration associated with the 'supra-rational', the masculine and the individual. This paper will focus, in particular, on the work of the sociobiologist Ellen Dissanayake and of the neuroscientist Antonio Damasio to investigate the importance of feeling, the feminine and sociality to the creative process. It will also take poetry as its focus, with the aim not of establishing a new methodology for writing poetry but of recognising the embodied condition from which poetry - regardless of what form it may take arises.

\section{A note on interdisciplinarity}

It is worth mentioning, as a further and final preliminary to this paper, that while interdisciplinarity is becoming increasingly popular, the relationship between the humanities and the sciences has been fraught. While not wishing to be polemical and 'take sides', I am nevertheless traversing a terrain of conflict in which I need to situate myself in under to be properly understood.

The 1990s, in conjunction with the 'culture wars', saw the emergence in the US of the so-called 'science wars', during which humanities and science scholars fought over which side might claim greater knowledge of human 'nature' (Ross 1996). The conflict was triggered, in part, by the emergence of the interdisciplinary area of science criticism, influenced by the humanities, which exposed how the empirical work of science was compromised by its allegiance to dominant ideologies and vested interests. Some scientists responded to this challenge to their objectivity and authority by discrediting the humanities, mocking postmodern relativism and ideological criticism in particular. In a 1996 hoax, the physicist Alan Sokal published a paper in the humanities journal Social Text, in which he satirically argued that quantum gravity was a social and linguistic construct (Sokal 2000). In 1998 EO Wilson advocated for 'consilience' or disciplinary convergence, heralding the inevitable and desirable replacement of misguided humanities epistemologies with scientific ones (Wilson 1998). In Literary Darwinism: Evolution, Human Nature, and Literature, Joseph Carroll presents a provocative version of Wilson's case: 
In the humanities, scholars happily confident of their own avant-garde creativity continue to repeat the formulas of Freud, Marx, Saussure, and Levi-Strauss - formulas that have now been obsolete, in their own fields, for decades. It is as if one were to visit a country in which the hosts happily believed themselves on the cutting edge of technological innovation and, in support of this belief, proudly displayed a rotary-dial phone, a manual type-writer, and a mimeograph machine. (Carroll 2004: $x$ )

Carroll hails the inevitable conquest of literary studies in particular by sociobiology and looks forward to a future in which literary texts will be assessed not for their ideological values but for whether or not they realistically reflect 'human nature'. Jonathan Gottschall, the author of Literature, Science, and a New Humanities, similarly declares that moving 'closer to the sciences in theory, method, and governing ethos' is 'the only responsible and attractive correction of course ... with the potential to lift the field from its morass' (Gottschall 2008: 3). Providing a model of the future of literary studies, Gottschall claims to restore 'dignity' to The Iliad by reading it as 'a drama of naked apes' (Gottschall \& Sloan Wilson 2005: xvii) - male ones at any rate.

I am not completely unsympathetic to concerns about the static nature of humanities scholarship, as my own frustration with the limitations of theories of creativity when it comes to literature suggests. However, the 'progressive' vision of Darwinian evolution that Wilson et al advocate as a universal paradigm itself comprises an outdated discourse, consistent with the retrograde ideologies of patriarchy, white supremacy and capitalism. Indeed, revisionary evolutionary scientists such as Lynn Margulis and Dorion Sagan reject neoDarwinists such as Wilson, Carroll and Gottschall as 'a minor, twentiethcentury sect' (Margulis \& Sagan 1997: 281). Contrary to the rhetoric of masculine competition and genetic determinism that neo-Darwinists employ, current science locates life in mutuality and struggle, and in complex and heterogeneous systems that give rise to 'interactive emergence' (Oyama 2000: 65)

While nature/nurture debates, typically mobilised by neo-Darwinists to uphold some ideological model of human nature, are given media attention, science has also moved beyond such simplifications. As Russell Gray argues, outlining Susan Oyama's development systems theory, the two categories of genes/environment, nature/nurture or innate/learned:

expand, interamify, and coalesce, and thus cease to be meaningful. All phenotypes are the joint product of internal and external factors. Development is one process requiring many inputs linked together by complex, nonlinear, dynamic systems. It cannot be realistically chopped in two. (Gray 1997: 390)

Francisco Varela, Evan Thompson and Eleanor Rosch point out, for instance, how the ultraviolet vision of bees and ultraviolent reflective patterns of flowers suggest a 'mutual enfoldment view of life and world' (Varela, Thompson \& Rosch 1997: 200). Even non-behavioural characteristics such as height and bone density rely on environmental inputs (such as nutrition or gravity) as much as genetic ones. Life is always embedded in multiple developmental systems, which include society and culture.

It remains the case, however, that despite valuing the work of Dissanayake and Damasio - which I will situate in the revisionary context just articulated when I come to outlining their theories below - I am no advocate of consilience. I 
share John Adams's concerns about the detrimental effect of 'methodological monism across the disciplinary spectrum' (Adams 2007: 134). However, what science can offer is precisely a challenge to the 'methodological monism' of the humanities - just as the revisionary evolutionary science referenced above undoubtedly derives in part from humanities interventions. While disciplinary specificities provide genuine obstacles to mutual understanding, we might find ourselves inspired and reinvigorated by attempts at exchange.

As Brophy has already demonstrated in the area of creative writing, interdisciplinary engagement can lead to fresh and exciting shifts in perspective. In Patterns of Creativity, Brophy calls attention to the ways in which the 'bewildering diversity of hypotheses, trials, variations and follies that the process of evolution has manifested on the planet' (Brophy 2009: 18) find productive parallels in the excess, spontaneity, provisionality and unpredictability of human creativity. What Brophy introduces here is the potential for a paradigm shift in thinking about creative practice. In this paper, I similarly hope to canvas the possibility of theorising creativity in ways that move beyond (whether that is to challenge or supplement) a tradition of thought within humanities scholarship.

\section{Dissanayake: the origins of creativity in 'motherese'}

While there is, as Gemma Corradi Fiumara reminds us, an enduring Cartesian tradition of conceptualising emotions as forces that 'cloud the vision of the intellect' (Fiumara 2001: 37), feelings have undergone a significant reevaluation in the humanities in recent times. In literary studies, for instance, we have seen the so-called 'ethical turn', which ascribes morally useful empathy-raising powers to books. The trend tends towards idealising literary feeling as a civic virtue (as we see in the work of Martha Nussbaum, 1995). However, there has also been the less didactic 'affective turn', challenging New Criticism's sanctioning of detached masculine appraisal over feminine absorption when it comes to reading. The ARC Centre of Excellence for the History of Emotions in Melbourne is a major initiative in this research area. In the discipline of creative writing, there are studies such as Albert Rothenberg's Creativity and Madness: New Findings and Old Stereotypes (1990) and Daniel Nettle's Strong Imagination: Madness, Creativity and Human Nature (2001), which reassess the role of emotion vis-à-vis the production of literature although such studies might be seen as continuing a more long-standing trend of psychoanalytic or psychological interpretations of creativity.

Such shifts in the humanities are inseparable from scientific studies demonstrating how our affective life, as Fiumara argues, cannot be compartmentalised away from our ratiocinative capabilities: emotion and cognition are 'based on continuities and transformations than on some conceptual taxonomy' (Fiumara 2001: 65). Emotions are a primary and 'important source of knowledge' (79), triggering attention and action, and they underlie every 'rational' decision we might make. Indeed, emotions form the constant, if changing, weather of our bodies. Importantly for this paper, Fiumara describes language - often associated with cognitive values in the Western philosophical tradition - as part of the 'affective reality in which we live and operate' (65).

It is a vision of language that makes immediate phenomenological sense to me as a poet. It also resonates with the Romantic and psychoanalytic understanding of poetic creativity as a 'supra-rational' (if mystified) experience, and while it contrasts with the postmodern emphasis on textuality, understanding affectivity 
as the foundation of our language experience is hardly undermined by a postmodern self-conscious repudiation of feeling, as I will argue shortly. This affective vision of language is also one elaborated on by the sociobiologist Dissanayake, whose work comprises a notable contribution to the scientific reassessment of emotion referred to above and, as I will now argue, an exciting interdisciplinary intervention when it comes to theorising creativity, particularly in relation to poetry.

Dissanayake's research highlights the fundamental significance of feeling to our cultural endeavours, draws attention to the role of women when it comes to nurturing feeling, and highlights the significance of mutual rather than individual feeling. Indeed, relying on a revisionary sociobiological methodology, she grounds creativity not in the imaginative faculty of men of original genius, but in maternal emotion and mutuality.

In Art and Intimacy: How the Arts Began, Dissanayake begins by defining art in terms of its emotional effect on audiences, comparing it with love. Love and art, she writes, 'grasp us utterly and transport us from ordinary sweating, flailing, imperfect "reality" to an indescribable realm where we know and seem known by the sensibility of another, united in a continuing present, our usual isolation momentarily effaced' (Dissanayake 2000: 4). She then traces the 'origins and interconnections of the felt rhythms and modes of love and art ... to ... the earliest months of individual infancy' (9), locating art's origins in the relationship between mother and child, and in the innate 'sensitivities and capacities that predispose them to join in emotional communion' (6). The first evidence of the mutual forces of love and art, Dissanayake argues, are to be found in 'baby talk' or 'motherese', which 'is not the trivial or inane pastime that it might superficially seem but, rather, a cradle in which nascent psychosocial capacities can emerge and be developed' (Dissanayake 2001: 336). Motherese is, for Dissanayake, the 'mutual multimedia ritual performance' (2000: 29) that emerges in the first months of infancy and motherhood, and that achieves its effects 'through fundamentally aesthetic means': 'stylization (formalization or simplification), repetition, exaggeration, and elaboration in visual, vocal, and gestural modalities' (2001: 336). During this multimedia performance, mother and infant collaborate in a routine of sound-making and face-pulling, the excitable mirror neurons in their brains compelling them to imitate one another's sounds and expressions so that they achieve what Dissanayake describes as an 'emotional communion'

(Dissanayake 2000: 6).

Dissanayake is explicit in contesting the cognitive bias of traditional accounts of language development. She argues that love and art, like the condition of infancy from which they arise, are 'intrinsically nonverbal' (Dissanayake 2000: 6) and non-cognitive in the strict old-fashioned sense of that term. While language, she argues, 'will eventually become also an instrument of symbolic reasoning and intellectual analysis', it first and foremost 'expresses emotional needs of mutuality and belonging' (45-6). In fact, for Dissanayake the emotional role of art remains paramount even in culture's more mature manifestations, with 'ceremonies or rituals' - from church services to cinema viewing and concerts - doing for a society's members 'what mothers naturally do for babies: engage their interest, involve them in a shared rhythmic pulse, and thereby instill feelings of closeness and communion' (64). Distinctions between the emotional and cognitive are always spurious, however, for that emotional communication is also profoundly - and not in any way idealistically - educative: 'Far from creating a state of soporific oceanic bliss, the elements of mother-infant engagements ... gain attention, guide emotions, and reinforce memory' (142). Indeed, they lie behind our eventual interpellation into ideology and come to form one of the developmental systems from which 
human 'nature' dialectically emerges (with 'nature' being inextricable from an environment that includes 'culture', as I suggested earlier).

To summarise, then, Dissanayake's theory of creativity is fundamentally emotional; the capacity for emotion and therefore creativity is developed by the mother; and creativity is grounded in a mutuality that always presumes and invites an audience. Indeed, in regards to the last point, it is notable that Dissanayake's conceptualisation of creativity does not attempt to separate the creator from the consumer; she never elevates the writer above the reader. Creativity is embedded in intersubjectivity rather than alienation - even if a feeling of alienation is what is being expressed.

As we can see, Dissanayake contests the traditional mythos of creativity based on the mystical 'supra-rational' mind, the masculine and autonomy. However, it is her distance from humanities debates around creativity that gives her work its originality and rigour. Dissanayake is not writing back to Romanticism, psychoanalysis or postmodernism, which are not in her purview. Her theory of creativity relies on a vision of human 'nature' that is, as I have suggested, selfconsciously revisionary, challenging the Cartesian, patriarchal and individualistic biases of traditional Darwinian evolutionary theory - something that is worth briefly addressing here.

Dissanayake understands human nature in terms of 'psychological or emotional needs that arise from a primary capacity for mutuality' rather than 'competitive behavioral strategies that serve an underlying selfishness' (Dissanayake 2000: 8). She argues: 'the earliest ability of infants is to ... engage in emotional communication with others. Each of us is born with a mind - sense and emotions - that moves us to seek and engage in intimacy with others before we do anything else' (10). Presupposing an environment of health in which mutuality can flourish, that intimacy is expressed and elaborated on through art. Nevertheless, cruder scientific models of culture's origins continue to rehearse the argument that, much as male peacocks allegedly produce their elaborate tail feathers to attract plainer females, men produce art in order to captivate fertile women. Steven Pinker, one such theorist, is critical of what he describes as utopian 'left-wing innatists' (Pinker 2002: 305) such as Dissanayake and Sarah Blaffer Hrdy, who also argues that maternal empathy drove language acquisition (Blaffer Hrdy 2009: 38) and that culture originated in adaptive systems of mother-infant 'mutual delight' (163). However, Dissanayake's emphasis on empathy and cooperation arguably provides a view of human evolution that is less naïve than traditional accounts privileging masculine competition for breeding rights. Dissanayake's work ultimately acknowledges how much more there is at stake to human reproductive success and survival - to 'fitness' - than rivalry between men for mates. Successful reproduction involves something more sustained and significant than the procreative act: namely, parenting. This is where 'motherese' - seen as the earliest form of 'art' - comes in, facilitating bonding and pleasure in a virtual performative space through the triggering and sharing of heightened emotion. It is also the case that, when it comes to understanding that subject dear to NeoDarwinists, human nature, Dissanayake's focus on infants and 'the prePaleolithic infancy of the human species' (Dissanayake 2000: 6) makes more sense than focusing exclusively on the behaviors of grown males.

Dissanayake's vision of poetry as intrinsically linked with emotion also makes sense to me as a poet, as well as resonating with Romantic theories of creativity. There are many different styles of poetry and compositional methods, but poetry might nevertheless be defined as 'originally lyric', as a type of language that fundamentally relies on 'feeling effects' - even if those feeling effects might be deliberately minimised, as in some examples of 
postmodern poetry. Poetry is principally a form of language that, as Ronald Schleifer describes, revolves around 'the phenomenal materiality of language' (Schleifer 2009: 85). Poetry is, likewise for Derek Attridge, 'a linguistic practice that specifically emphasizes the material properties of language ... [that] provide pleasure and significance independently of cognitive content' (Attridge 1988: 130). Poetry is typically attuned to the 'felt' dimensions of language apparent in its rhythms, sounds, textures, and rhymes. Poetry is also commonly associated with connotative or suggestive, rather than denotative or instrumentalist, kinds of expression. All of this is to say that poetry, as the common complaint of students articulates, is not primarily about conveying a 'rational' sense of things - although it can, in a self-reflexively counterintuitive mode, adopt such approaches when it chooses. Indeed, poetry is a frequent even formalised - response to experiences of emotional intensity that are difficult to cognitively process and articulate, such as love, pain, trauma, or grief. Poetry, with its reliance on 'feeling effects', suggestion, rhyme, and musicality, becomes an intuitive or self-consciously employed resource for expression during deeply experienced 'feeling events' that do not translate easily into words. It is in this light that Schleifer describes poetry as a 'primal cry' for a state of expression 'in which the distance between signifier and signified, between sound and import, does not exist' (Schleifer 2009: 87); poetry pushes 'toward the "rediscovered truth" of a simple rather than a double articulation' (95).

Poetry, as I have described it here, can be a profoundly moodful and intimate praxis. This could be why poetry sometimes feels 'auto-intoxicated' (Moffitt 2005: 20), as representations of poetry from ancient Greece through to the contemporary day have it. Romantic and psychoanalytic theories of creativity might glorify poetry as the narcissistic exercise of the emotional genius. However, poetic attempts at expressing a felt experience of the world assume, as Dissanayake would argue, the presence of a 'Virtual Mother' (2000: 48), an intimate, sympathetic audience ready to receive, recognise, mirror, and respond. Indeed, we might say that the act of writing poetry comes from the 'Virtual Mother'; it is invited by a tradition of emotional creativity and communication that was instituted for us. Indeed, inspiration so often comes directly from reading poetry or participating in another moodful cultural stimulus, such that we feel prompted to express our emotional experience in reply. This resonates with Dissanayake's description of the mother-infant cultural dynamic of 'matching or imitating another person's expressed states ... thus making it possible to enter into or share the others' feeling' and to enhance 'one's own mood or state' (40).

In Patterns of Creativity Brophy quotes from a 1929 book by Mary Cecil Allen that notably addresses modern art's non-figurative and expressionist tendencies. Cecil Allen asks an artist why she paints, and the artist responds: 'Because things I see excite me and I want to reproduce this feeling' (cited in Brophy 2009: 53). Brophy suggests that a similar emotion is basic to why he writes poetry, although he also notes how writing poetry is a highly selfconscious exercise. Because we write from a tradition, he argues, a poem is also always about poetry. Poetry's self-reflexive intertextuality is why a poem can choose to strip itself of its emotionalism, inspired by particular philosophical or ideological fashions, as we see with some examples of preRomantic Classical verse or postmodern poetry. However, poetry, with its roots in orality, can be viewed as fundamentally about emotion, originally grounded in the maternal dyad of emotional communication, and intrinsically attached to the possibility of an intimate audience. 


\section{Damasio: creativity as an expression of the 'embodied mind'}

As we have seen, Dissanayake's theory of art's origin in motherese invites us to recognise emotion, a maternal context of intimacy, and mutuality as key features of creativity. Surveying Antonio Damasio's research in neuroscience allows us to test these ideas from a different disciplinary vantage point. The discussion of Damasio's work will rely on his theoretical articulations of his clinical research, rather than on his clinical research per se, because of the latter's specificity. In popular science 'trade books' such as The Feeling of What Happens (Damasio 1999) and Self Comes to Mind: Constructing the Conscious Brain (Damasio 2012a), Damasio highlights the importance of emotion and feeling to the functioning of the modern brain and the existence of the conscious mind - that traditional seat of the self, so firmly associated with cognition in the Cartesian model. Indeed, in a 2012 lecture for the Brain and Creativity Institute at the University of Southern California (Damasio 2012b) the seat of Damasio's interdisciplinary research - like Dissanayake he locates the origin of creativity in a maternal context of emotional bonding. Damasio's work therefore enables us to further demystify 'supra-rationalist', masculinist and alienated representations of the creative practitioner.

Damasio's research forms part of the 'affective turn' apparent even in the socalled cognitive sciences (a term used as a catch-all to include neuroscience, phenomenology, various branches of cognitive science, and consciousness studies). As F Elizabeth Hart explains:

whereas an earlier phase of cognitive science focused its energies on Artificial Intelligence and on theories of language and psychology that supported AI, grounding its theories implicitly in a metaphor of the mind as a computer, today's cognitive scientists tend to concentrate instead on the more organic metaphor of the "embodiment" of mind, that is, of the mind's substantive indebtedness to its bodily, social, and cultural contexts . . . all of which contribute to recasting human reason into a set of highly imaginative - not logical but figural - processes. (Hart 2001: 315)

N Katherine Hayles expands on the implications of such an epistemological shift for the philosophical tradition of Cartesian dualism, which valorises ratiocinative processes:

If one accepts the fundamental continuity between body and mind, thought is essentially like all other physiology and behavior. Thinking, like excreting and ingesting, results from lively interactions of a being's chemistry. Even "microbial" thinking derives from cell hunger, movement, growth, association, programmed death, satisfaction, and other intrinsica of all life. (Hayles 1996: 181)

Margulis and Sagan, further demystifying cogitation through a materialist grounding of the brain in the body, argue that all life is 'capable of choice, of decisions, of sensing and thinking. Such "thoughts", both vague and clear, are physical. They are in the cells of our bodies and in those of other animals' (Margulis \& Saga 1997: 181). Those thoughts, as Hart emphasises above, are patterned as much by the social and cultural as the biological systems from within which our lives emerge.

This shift from viewing the human mind as some kind of autonomous, transcendental, cogitating machine to the embodied mind has resulted in a 
concurrent revision of how consciousness is understood. Consciousness is no longer conceived as a ratiocinative 'self' controlling things from somewhere inside the brain. As Damasio argues, there is no 'homonculus' (or proverbial 'little man') sitting in the brain, thinking and making decisions (Damasio 1999: 11). Daniel Dennett, with whose research into consciousness Damasio engages, similarly argues that there is no 'ghost in the machine' (Dennett 1991: 35). In fact, consciousness arrives late by 500 milliseconds, so that self-awareness is not even necessary to the brain's capacity to make decisions and take action.

Consciousness, Dennett suggests, is a 'biological phenomenon - like metabolism or reproduction or self-repair' (Dennett 1991: 57) that has a 'recursive capacity' (Dennett 2005: 174), enhancing the brain's attentional and learning capacities, but it is not the privileged source of will or intentionality. Damasio concurs that consciousness provides 'more wakefulness and morefocused attention' (Damasio 1999: 182) - a sense of 'feeling' in control (Damasio 2012a: 280) and of feeling like 'you' (161) - rather than being paramount to decision-making and action.

Such research effectively consigns most thought to the realm of the unconscious, radically expanding that category of the mind, as well as dispelling the mysticism and pathology with which it has been traditionally associated in the humanities. The unconscious is not created by repressed fears and desires, as psychoanalysis would have it; it is not some kind of subterraneous, tortured realm ready to be explored by the creative genius bravely seeking psychological truth. Rather, as Damasio puts it, the unconscious provides a vast and flexible 'knowledge base' (Damasio 2012a: 144) that is essential to 'life management' (36). In fact, he argues: 'our cognitive unconscious is capable of reasoning and has a larger "space" for operations than the conscious counterpart' (275), which he portrays as 'in-themoment' (276) and easily distracted [1]. This understanding of the dynamic between unconscious and conscious processing offers a fascinating explanation, as Damasio explicitly suggests, for the 'aha' moment typically ascribed to inspiration; if creativity feels as if it comes from 'somewhere else', it is because the creative product comes into conscious awareness after the unconscious 'quiet delivery of the solution' (276).

Stressing the centrality of unconscious functioning to the human organism, Dennett provocatively argues that there is no difference between a human and a zombie. Both are unconscious creatures and, as such, 'behaviourally indistinguishable' (Dennett 1991: 86). Damasio adds nuance to Dennett's iconoclastic scenario, showing how the unconscious is educated according to 'conscious intentions and goals' (Damasio 2012a: 270). He also draws attention to the ways in which the brain stem, the primitive foundation of the modern brain, is fundamentally emotional so that human life-forms, unlike zombies but like most other organisms, are thus essentially emotional: 'Primordial feelings are not only the first images generated by the brain but also immediate manifestations of sentience' (2012a: 22). If there is a distinction to be made between a human and a zombie - or a computer, which provides Damasio's point of comparison (1999: 314) - that dissimilarity lies in the emotional nature of the embodied mind, which responds to the sensory environments in which we live. Indeed, for Damasio, feeling provides nothing less than 'the backdrop for the mind, and, more specifically, the foundation for the elusive entity we designate as self' (30).

Damasio distinguishes between emotions, as 'actions accompanied by ideas and certain modes of thinking' (2012a: 110), and feelings, which he defines as 'perceptions of what our bodies do during the emoting' (110). According to Damasio, while emotions motivate simple and complex organisms alike, 'states of emotional feeling' (110) have developed only in more complex organisms 
such as humans and other mammals, bringing about consciousness of that emotional knowledge: 'The organism no longer had mere feelings that could be felt; it had feelings that could be known' (176). This is, for Damasio, the origins of consciousness, which comes with a 'definite quality, a valence, somewhere along the pleasure-to-pain range' (185). Indeed, for Damasio it is that combination of emotion and feeling that provokes humans to engage in the creation of art. Poetically evoking a potential feeling-rich scene of creativity, he argues:

No set of conscious images of any kind and on any topic ever fails to be accompanied by an obedient choir of emotions and consequent feelings. As I am looking at the Pacific Ocean dressed in its morning suit, protected by a soft, gray sky, I am not just seeing, I am also emoting to this majestic beauty and feeling a whole array of physiological changes that translate, now that you ask, into a quiet state of well-being. (Damasio 2012a: 254)

While consciousness has facilitated introspection, Damasio stresses that to be conscious is to feel conscious of something or someone. Consciousness requires 'two players, the organism and the object', and it is principally about 'the relationship those players hold' (1999: 133). For Damasio, consciousness is the felt knowledge that arises from your body's mapping of itself vis-à-vis spatial objects; it 'materializes when you confront an object, construct a neural pattern for it, and discover automatically that the now-salient image of the object is formed in your perspective, belongs to you, and that you can even act on it' (126). While Damasio's discussion does not extend to the primary relationship between mothers and children, the cognitive scientist Shaun Gallagher, in How the Body Shapes the Mind, identifies the origins of the conscious self precisely in the moodful maternal dynamic. Invoking the mother-and-infant system of imitation and mutuality encapsulated by Dissanayake's concept of 'motherese', Gallagher argues that such 'intermodal and intersubjective interaction' emotionally enhances the 'proprioception' or bodily awareness (Gallagher 2005: 73) of the infant, leading to selfconsciousness. It is a vision of healthful mutuality and individuation that contrasts starkly with Freud's or Lacan's theories of infant conflict and alienation, which might be seen to give expression to little more than tragic patriarchal fantasies of autogenesis.

Damasio and Gallagher also agree on the embodied and intersubjective origins of language. For Damasio, the 'moved' and 'moving' body is intrinsic to language development. He refers to clinical trials on stroke patients with akinetic mutism, whose motion impairment and emotional impairment are accompanied by speechlessness. By contrast, stroke patients with mobility impairment but without emotional impairment can feel their way back into words. Damasio also asserts that language development is dependent on mutuality and worldly embeddedness. He asks: 'Is it plausible to think that language utterances could be created in individuals who had no sense of self, other, and surroundings?' (Damasio 1999: 109) Gallagher further develops the ways in which early expressive movements and emotional vocalisations, of the kind seen in the interactive performances of motherese, provide the foundations for language acquisition (Gallagher 2005: 128). It is a view that relies, as Gallagher notes, on a condition of intersubjectivity (129). Once again evoking motherese, he argues: 'The body generates a gestural expression. It is, however, another person who moves, motivates, and mediates this process. To say that language moves my body is already to say that other people move me' (129). 
The earlier articulation of embodied consciousness and language development by the phenomenologist Maurice Merleau-Ponty is also useful to canvas at this stage [2]. For Merleau-Ponty, as for Damasio and Gallagher after him, the mind is embodied and, as such, shaped by motion and emotion. The mind also intrinsically belongs to what Merleau-Ponty describes as 'the system 'selfothers-things"” (Merleau-Ponty 1976: 57). Notably like a poet, Merleau-Ponty often allows his language to encapsulate the moodful and immersed condition he ascribes to human beings. He writes, for instance: 'Our own body is in the world as the heart is in the organism; it keeps the visible spectacle constantly alive, it breathes life into it and sustains it inwardly, and with it forms a system' (203). Merleau-Ponty also argues that language, as a product of the embodied mind, represents an embodied response to the world and therefore springs from motion and emotion. Speech is primarily a physical act; it is not about engaging with language on some ideal, cognitive plane, as the postmodernists might have it: 'the speaking subject plunges into speech without imagining the words he is about to utter'; it is 'a motor presence of the word which is not the knowledge of the word' (403). Emotion is profoundly imbricated with motion and, as Merleau-Ponty argues, with language, which is fundamentally an 'emotional' response to the world (188). It is the body, as 'the subject of perception' (225), which invests words with their significance, before words become codified as signs (235). For example, he contends: 'In so far as my hand knows hardness and softness, and my gaze knows the moon's light, it is as a certain way of linking up with the phenomenon and communicating with it' (317). Focusing on the word 'sleet', he argues that:

the word's meaning is not compounded of a certain number of physical characteristics belonging to the object; it is first and foremost the aspect taken on by the object in human experience, for example my wonder in the face of these hard, then friable, then melting pellets falling ready-made from the sky. (Merleau-Ponty 1976: 403)

Merleau-Ponty is explicit in contesting idealist or alienated concepts of language: language 'is not an attribute of external origin, in the sociologist's sense' (403). Evoking Romanticism's interest in the poet's felt immersion in a natural world, he writes: 'I am a field, an experience' that must "'have it out" with the world' (406-7). It is part of the 'irrational power' (189) or emotional proclivity of the self, he argues, to communicate and seek mutuality - a proclivity that can only have originated with the maternal dyad.

The poetic nature of Merleau-Ponty's prose provides me with a convenient way to return to this paper's argument that the problem of creativity, when it comes to poetry in particular, might be satisfactorily illuminated in terms of paradigms emerging in the sciences. Rather than theorising creativity in terms of a mystical 'supra-rational' activity, the genius of men, and originality - as per Romantic, psychoanalytic and postmodern traditions in the humanities - we might look to more empirically based but no less fascinating explanations in the sciences. Such explanations are compellingly and thoroughly consistent with the phenomenological interest of creative practitioners in expressiveness an interest valorised by Romantic and psychoanalytic theories of creativity, if underplayed by postmodernism. However, considered in the theoretical contexts provided by sociobiology and the cognitive sciences, the 'selfexpressive' is usefully deprived of the self-aggrandising mystificatory tendencies of which Moffitt complains in his survey of enduring myths of creativity in the humanities (Moffitt 2005: 14). Indeed, if we understand expressiveness in the light of sociobiology and cognitive science - while appreciating, as Moffitt suggests, that self-expression is no guarantee of cultural value (340) - emotional expressiveness becomes far less irritating. It 
becomes less a matter of the snobbery (216) and martyrdom (213) that Moffitt identifies, and more a matter of egalitarian and healthy compulsion.

For Dissanayake and Damasio, the urge to be creative develops in emotional contexts of maternal mutuality and worldly embeddedness - an experience that is germane to us all - rather than within patriarchally conceived systems of supra-logic and alienation. Emotional expressiveness is central to the process. The research of Dissanayake and Damasio (as well as of their contemporaries) suggests that, to revise Descartes' maxim, 'I feel therefore I am'. Notably, in its lyric form, poetry is understood to be the narcissistic expression of the momentary experiences of the 'felt I' that Damasio evokes as the phenomenological experience of embodied consciousness. Moffitt might complain that lyric poems, because of their association with self-expression, have become 'increasingly incomprehensible to the degree that they become ever more private, and so inherently ever-more subjective ... even functionally autistic' (Moffitt 2005: 206). However, the practice of writing lyric poetry cannot be viewed as entirely narcissistic if we appreciate the intersubjective precondition of expressive articulation - something highlighted by postmodern poetry's intertextual emphasis. Of course, as I have suggested, some examples of postmodern poetry might disavow lyricism and expressiveness. Thanks to the recursive function of consciousness, it is always the case that poets can refigure the qualities of their verse, perhaps even to occlude the feeling body in favour of a cognitive and alienated vision of themselves. Nevertheless, the embodied mind and its emotional language remain fundamental to poetic creativity - something that Dissanayake's work in sociobiology and Damasio's research in neuroscience confirms.

\section{Conclusion}

As suggested in the preliminaries to this paper, I am not advocating 'consilience' or a methodological monism for the humanities based on new work in the sciences. I hope merely to highlight how epistemologies emerging in the sciences might enable us to rethink key issues pertinent to creativity in the humanities. Indeed, it is not even the case that challenging Romantic, psychoanalytic or postmodern ways of thinking about creativity implies rejecting them. I hope that my essay has suggested possibilities for a more materially grounded understanding of, for example, the 'supra-rational' quality mystified by the Romantics and psychoanalysis in connection with creative activity. There is also significant potential to begin reconceptualising the relationship between the unconscious and the conscious when it comes to creativity. What I would like to advocate here is an interdisciplinary approach to the problem of creativity that might best be encapsulated by the motif of Yeats's 'long-legged fly', which touches lightly upon the profound stream of ideas - a stream that passes through many different disciplines, just as it passes, in Yeats's' poem, through the minds of many different creative personalities. Might the light touch of the long-legged fly provide an image for an interdisciplinary methodology that tests new possibilities, rather than remaining fixed to one stream of knowledge?

\section{Notes}

[1] While consciousness is a transient occurrence, it seems continuous and stable, as Damasio argues, because it is 'renewed again and again thanks to anything that comes from outside the brain into its sensory machinery or anything that comes from the brain's memory stores towards sensory, motor, or autonomic recall' (1999: 172). return to text 
[2] While Damasio has been criticized for neglecting the work of Merleau-Ponty, he addresses the connections between their work in 'Mind, Body, and Mental Illness' (Damasio 1998). return to text

\section{Works Cited}

Adams, J 2007 Interference Patterns: Literary Study, Scientific Knowledge, and Disciplinary Autonomy, Bucknell University Press, Lewisburg PA return to text

Attridge, D 1988 Peculiar Language, Cornell University Press, Ithaca NY return to text

Blaffer Hrdy, S 2009 Mothers and Others: The Evolutionary Origins of Mutual Understanding, The Belknap Press of Harvard University Press, Cambridge MA return to text

Brophy, K 2009 Patterns of Creativity: Investigations into the Sources and Methods of Creativity, Rodopi, Amsterdam return to text

Busse, TV \& RS Mansfield 1980 'Theories of the Creative Process: A Review and Perspective', The Journal of Creative Behavior 14, 2: 91-132 return to text

Carroll, J 2004 Literary Darwinism: Evolution, Human Nature, and Literature, Routledge, New York return to text

Clark, T 1997 The Theory of Inspiration: Composition as a Crisis of Subjectivity in Romantic and Post-romantic Writing, Manchester University Press, Manchester return to text

Damasio, AR 2012a Self Comes to Mind: Constructing the Conscious Brain, Vintage, London return to text

Damasio, AR 2012b 'Evolutionary Origins of Art and Aesthetics: Art and Emotions', Public lecture, University of Southern California: http://www.uctv.tv/shows/CARTA-EvolutionaryOrigins-of-Art-and-Aesthetics-Art-and-Emotions-Antonio-Damasio-16432 (accessed 15 January 2014) return to text

Damasio, AR 1999 The Feeling of What Happens: Body and Emotion in the Making of Consciousness, Harcourt Brace, New York return to text

Damasio, AR 1998 'Mind, Body, and Mental Illness', Philosophy, Psychiatry, and Psychology $5,4: 343-45$ return to text

Dennett, D 2005 Sweet Dreams: Philosophical Obstacles to a Science of Consciousness, MIT Press, Cambridge MA return to text

Dennett, D 1991 Consciousness Explained, Little Brown, Boston return to text

Dissanayake, E 2001 'Aesthetic Incunabula', Philosophy and Literature 25, 2: 335-46 return to text

Dissanayake, E 2000 Art and Intimacy: How the Arts Began, University of Washington Press, Seattle return to text

Faflak, J 2007 Romantic Psychoanalysis: The Burden of the Mystery, SUNY Press, New York return to text

Fiumara, G Corradi 2001 The Mind's Affective Life: A Psychoanalytic and Philosophical Inquiry, Brunner-Routledge, Hove East Sussex return to text

Gallagher, S 2005 How the Body Shapes the Mind, Clarendon Press, Oxford return to text

Gottschall, J 2008 Literature, Science, and a New Humanities, Palgrave Macmillan, New York return to text

Gottschall, J \& D Sloan Wilson (eds) 2005 The Literary Animal: Evolution and the Nature of Narrative, Northwestern University Press, Evanston IL return to text 
Gray, R 1997 “"In the Belly of the Monster”: Feminism, Developmental Systems, and Evolutionary Explanations', in P Adair Gowaty (ed) Feminism and Evolutionary Biology: Boundaries, Intersections, and Frontiers, Chapman \& Hall, New York: 385-413 return to text

Hart, FE 2001 'The Epistemology of Cognitive Literary Studies,' Philosophy and Literature 25, 2: 314-34 return to text

Hayles, NK 1993 'Constrained Constructivism: Locating Scientific Inquiry in the Theatre of Representation', in G Levine (ed) Realism and Representation: Essays on the Problem of Realism in Relation to Science, Literature, and Culture, University of Wisconsin Press, Madison WI: 27-43 return to text

Margulis, L \& D Sagan 1997 Slanted Truths: Essays on Gaia, Symbiosis, and Evolution, Copernicus, New York return to text

Merleau-Ponty M 1976 (1962) Phenomenology of Perception, trans C Smith, Routledge \& Kegan Paul, London return to text

Moffitt, JF 2005 Inspiration: Bacchus and the Cultural History of a Creation Myth, Brill, Leiden return to text

Nettle, D 2001 Strong Imagination: Madness, Creativity, and Human Nature, Oxford University Press, Oxford return to text

Nussbaum, M 1995 Poetic Justice: The Literary Imagination and Public Life, Beacon Press, Boston return to text

Oyama, S 2000 Evolution's Eye: A System's View of the Biology-Culture Divide, Duke University Press, Durham return to text

Perloff, M 2010 Unoriginal Genius: Poetry by Other Means in the New Century, University of Chicago Press, Chicago return to text

Ross, A (ed) 1996 Science Wars, Duke University Press, Durham return to text

Rothenberg, A 1990 Creativity and Madness: New Findings and Old Stereotypes, The Johns Hopkins University Press, Baltimore return to text

Schleifer, R 2009 Intangible Materialism: The Body, Scientific Knowledge, and the Power of Language, University of Minnesota Press, Minneapolis return to text

Sokal, AD 2000 'What the Social Text Affair Does and Does Not Prove: A Critical Look at "Science Studies", in KM Ashman \& PS Baringer (eds) After the Science Wars: Science and the Study of Science, Routledge, Florence KY: 13-28 return to text

Varela, FJ, E Thompson \& E Rosch 1997 (1991) The Embodied Mind: Cognitive Science and Human Experience, MIT Press, Cambridge return to text

Wilson, EO 1998 Consilience: The Unity of Knowledge, Alfred A Knopf, New York return to text

Dr Maria Takolander is a Senior Lecturer in Literary Studies and Professional and Creative Writing at Deakin University in Geelong, Victoria. She is the author of three books of poetry, The End of the World (Giramondo 2014), Ghostly Subjects (Salt 2009) and Narcissism (Whitmore Press); a short-story collection The Double (Text 2013); and a work of literary criticism, Catching Butterflies: Bringing Magical Realism to Ground (Peter Lang 2007). She is currently working on a novel, Transit, for Text Publishing. 


\section{TEXT}

Vol 18 No 2 October 2014

http://www.textjournal.com.au

General Editor: Nigel Krauth. Editors: Kevin Brophy, Enza Gandolfo \& Linda Weste

text@textjournal.com.au 